* Doutor em Direito. Professor da Universidade Federal de Pernambuco (UFPE) e da Universidade Católica de Pernambuco (UNICAP). Desembargador do TRT6. Líder do Grupo de Pesquisa LOGOS. E-mail: sergiotteixeira@uol. com.br

**Especialista em Direito Processual Civil pelo Centro Universitário de João Pessoa (UNIPÊ). Aluno Especial da PósGraduação em Direito Processual Civil a Nível de Mestrado da Universidade Católica de Pernambuco(UNICAP). Graduado em Direito. Pesquisador.E-mail: eneassarmento@hotmail.com

\section{Concessão liminar da Tutela da EvidênCIA EM Mandado de Segurança em Matéria Tributária}

\author{
Preliminary Concession of Relief Based on Prima Face \\ Evidence Within a Writ of Mandamus on Tax Matters
}

\section{Sergio Torres Teixeira* Enéas César Douetts Alves**}

Como citar: TEIXEIRA, Sérgio Torres; ALVES, Enéas César Douetts. Concessão liminar da tutela da evidência em mandado de segurança em matéria tributária. Revista do Direito Público, Londrina, v. 15, n. 2, p. 177-194, ago. 2020. DOI: 10.5433/24157-108104-1.2020v15n2p. 177. ISSN: 1980-511X

Resumo: O Código de Processo Civil, aprovado pela Lei $\mathrm{n}^{\mathrm{o}} 13.105$ de 16 de março de 2015, traz um novo horizonte na forma de se contemplar o processo, introduzindo significativas mudanças no que concerne ao sistema processual. Dentre elas, pode-se citar a forma antecipatória dos efeitos de uma decisão final: a tutela de evidência, nos moldes do art. 311, inciso II, do CPC, sendo mais inovadora ainda a sua possibilidade por liminar. Objetiva-se, portanto, saber a viabilidade da concessão dessa tutela em mandado de segurança para suspensão do crédito tributário. Trata-se de uma das mais interessantes implicações da legislação processual em relação ao direito tributário. Isso porque, nos termos do inciso IV do artigo 151 do Código Tributário Nacional, liminar em mandado de segurança é causa de suspensão de exigibilidade, potencial que se estenderia às tutelas de evidência após o seu surgimento. Para tanto, analisa-se o direito de evidência, a medida liminar, a tutela de evidência por liminar e, ao final, faz-se a análise acerca da possibilidade da concessão liminar da tutela da evidência em sede de mandado de segurança para obter a suspensão do crédito tributário. $\mathrm{O}$ objetivo principal da investigação será averiguar se com o advento da tutela da evidência disciplinada pelo CPC de 2015, surgiu uma nova ferramenta para proceder à sustação da cobrança de tributos. O estudo será desenvolvido mediante uma análise crítica da doutrina mais recente acerca da temática, com um método de abordagem dedutiva e um método de procedimento comparativo. Com o presente, almeja-se definir se é possível conceder liminarmente a tutela da evidência em sede mandado 
de segurança em matéria tributária.

Palavras-chave: Tutela da evidência. Medida Liminar. Mandado de segurança. Crédito tributário.

\begin{abstract}
The Brazilian Code of Civil Procedure, approved by Federal Law 13.105 of 2015, brings a new horizon in the way of contemplating the judicial process, introducing significant changes in what concerns the procedural system. Among them, the anticipatory form of the effects of a final decision through the relief granted on the basis of prima facie evidence, in the form of article 311, item II, of the Code of Civil Procedure. And said relief can be provided in an even more innovative style, through the possibility of a preliminary injunction. In that context, it is relevant to know the viability of this relief in a writ of mandamus to suspend the collection of taxes. This is one of the most interesting implications of procedural legislation in relation to tax law, because it is recurrent to use the writ of mandamus in this matter, as well as, under the terms of item IV of article 151 of the Brazilian National Tax Code, injunction security is a cause of suspension of enforceability, a potential that would extend to the relief granted on the basis of prima facie evidence. In order to do so, it is necessary to proceed through the examination of the relief of evidence, the preliminary injunction, the protection of evidence by preliminary injunction so that, in the end, the analysis will evaluate the possibility of using the relief of evidence through a preliminary injunction within a writ of mandamus for the suspension of tax credit.
\end{abstract}

Keywords: Relief of Evidence. Preliminary Injunction, Writ of Mandamus. Tax Credits. 


\section{INTRODUÇÃO}

O legislador de 2015, por meio da Lei $\mathrm{n}^{\mathrm{o}} 13.105$ (BRASIL, 2015), consagrou no ordenamento jurídico pátrio o atual Código de Processo Civil (CPC), introduzindo no modelo processual brasileiro a figura da tutela provisória. Este instrumento, como contraponto à tutela final materializada quando da conclusão de um processo judicial, corresponde à proteção jurisdicional proporcionada por meio de um provimento apto a gerar efeitos jurídicos materiais antes da entrega da prestação jurisdicional definitiva ao término da relação processual. Enquanto a tutela final somente é obtida após a concretização de uma prestação judicial na etapa de cumprimento de sentença em subsequente ao reconhecimento do direito em uma fase cognitiva exauriente (no caso de um processo de conhecimento típico) ou dentro de um processo de execução autônomo (no caso de uma execução fundada em título executivo judicial), a tutela provisória constitui uma tutela jurisdicional precária e interina, concedida sem exaurimento da cognição judicial, com o objetivo de proporcionar o adiantamento (total ou parcial) dos efeitos da tutela final (quando o provimento assume natureza antecipatória) ou então conservar o objeto do processo e preservar a sua utilidade prática (quando a medida revela natureza cautelar).

O artigo 294 do CPC de 2015, no seu caput, expõe duas espécies de tutela provisória, a tutela de urgência e a tutela da evidência, dicotomia esta baseada no fundamento principal de concessão da respectiva medida. Quando o motivo maior que justifica a medida é a existência de uma situação de periclitância, evidenciada pelo risco de dano ou ameaça à serventia do processo, surge a tutela de urgência. Quando o fundamento da concessão é a configuração nos autos de uma situação enquadrável em uma das hipóteses tipificada pelo legislador como de "evidência" do direito, no sentido de estar retratado um caso de alto probabilidade de acolhimento da pretensão da parte postulante.

Na tutela da evidência, é desnecessária a demonstração do periculum in mora que é indispensável à concessão da tutela de urgência. Nesta, o risco de dano ou a ameaça à utilidade do processo é imprescindível, sendo igualmente exigida a existência de elementos aptos a demonstrar a "probabilidade" do direito (artigo 300 do CPC). Naquela, não basta a mera plausabilidade do direito invocado: é necessário encontrar nos autos elementos que permitam o enquadramento em um dos tipos legais descritos como de evidência do direito, quando os elementos evidenciem a grande viabilidade da prevalência da tese, em um patamar logo abaixo da "certeza" processual que permite o julgamento do mérito após cognição exauriente.

A tutela da evidência, por seu turno, é disciplinada especificamente no artigo 311 do CPC de 2015, apresentando dentre outras características o fato de seu provimento ter natureza nitidamente antecipatória (e não cautelar) e a sua concessão ser necessariamente incidental (e não antecedente), em contraponto à tutela de urgência, cujo provimento pode ser de índole cautelar ou de natureza antecipatória e concedido de modo incidental ou antecedente (antes mesmo da apresentação formal do pedido principal de tutela final). Apesar do artigo 331 elencar variadas hipóteses de evidência nos seus quatro incisos, tal elenco não é exaustivo, uma vez que outros 
dispositivos legais disciplinam casos análogos, como o artigo 562 do próprio $\mathrm{CPC}$, ao tratar do mandado liminar de manutenção ou de reintegração da posse, nas ações possessórias.

A concessão liminar da tutela da evidência, por sua vez, merece um estudo à parte. Em que pese as restrições expostas no parágrafo único do artigo 311 do $\mathrm{CPC}$, que, ao repetir as restrições do artigo $9^{\circ}$, parágrafo único, inciso II, do mesmo diploma legal ao prever que apenas duas das quatro hipóteses de evidência do direito tratadas no artigo 311 podem autorizar a concessão initio litis e inaudita altera parte da respectiva modalidade de tutela provisória, é inegável a relevância da respectiva técnica de concessão nos mais variados cenários jurídicos.

A tutela da evidência por liminar, destarte, é um importante instituto do Direito Processual Civil moderno. No que concerne as suas implicações em relação ao Direito Tributário, trata de ponto a ser descrito em múltiplos estudos uma vez que é recorrente a utilização do mandado de segurança nessa matéria, assim como, nos termos do inciso IV do artigo 151 do Código Tributário Nacional (CTN), liminar em mandado de segurança é causa de suspensão de exigibilidade, potencial que se estenderia às tutelas de evidência.

A hipótese a ser defendida aqui é a de que há possibilidade de aplicação da tutela de evidência por liminar em mandado de segurança para a suspensão do crédito tributário. O Código Tributário Nacional só aventava essa possibilidade de liminar em sede de mandado de segurança. Com o advento da Lei Complementar n. 104/2001, passa-se a concessão de medida liminar, na forma de uma tutela provisória, como meio de suspensão da exigibilidade do crédito tributário, em outras espécies de ação judicial. Pretende-se, então, corroborar com as pesquisas nessa seara, demonstrando a pertinência dessa analogia.

O objetivo geral do presente trabalho, portanto, é o de explicitar a possibilidade de concessão de liminar da tutela da evidência em mandado de segurança em matéria tributária. Como objetivos específicos, têm-se os de discorrer sobre o "direito evidente", enfatizando a tutela de evidência, bem como o de explicar a liminar e os critérios de suspensão do crédito tributário, para, ao final, analisar a aplicação da liminar desta tutela em matéria tributária.

Para tanto, organiza-se o presente estudo da seguinte maneira: inicialmente, explicam-se noções gerais sobre o direito evidente; em seguida, adentra-se em questões acerca da tutela de evidência por liminar; em continuação, apresentam-se considerações sobre a liminar; e, só então, analisa-se a suspensão do crédito tributário de tutela da evidência por liminar em mandado de segurança.

A metodologia utilizada nesta pesquisa possui uma abordagem dedutiva de natureza crítica, com o uso do método comparativo fundado em uma pesquisa documental na literatura especializada e contemporânea.

\section{DIREITO EVIDENTE E TUTELA PROVISÓRIA DA EVIDÊNCIA}

A prática judiciária indica casos em que não se revela justa a demora da prestação jurisdicional, mercê de inexistir qualquer situação de perigo (FUX, 1996, p. 377). São hipóteses 
nas quais é prescindível a existência de um quadro de periculum in mora, como um risco de dano ao processo ou ao seu objeto ou mesmo uma ameaça que pode comprometer a própria serventia do processo judicial, mas há demonstração nos autos de fortes indicadores de um cenário no qual o direito à prestação pleiteada pela parte postulante deve ser reconhecido. Noutras palavras, é um quadro de alta probabilidade do acolhimento da pretensão deduzida em juízo, em virtude dos elementos constantes dos autos.

Tratam-se dos casos de evidência do direito ou de "direito evidente", quando antes do encerramento da fase cognitiva e do julgamento da causa, o direito da parte autora já se manifesta com bastante clareza nos autos do processo.

Não se trata de um quadro de "certeza" acerca do deslinde da demanda, pois tal status somente pode ser alcançado uma vez exaurida a etapa cognitiva correspondente com a conclusão da produção de provas quanto à respectiva matéria. A “certeza” processual, nesse sentido, somente poderá ser alcançada na demanda com o julgamento do mérito da questão por meio de uma sentença judicial, seja esta proporcionada mediante um julgamento antecipado do mérito (artigo 355 do CPC de 2015) ou por uma sentença ao final de toda a fase instrutória, seja a sentença integral (apreciando todo o objeto da postulação) ou parcial (abordando apenas uma parte dos pedidos, conforme permitido pelo artigo 335 do CPC de 2015).

Uma situação de evidência do direito corresponde a um fato jurídico processual que torna possível a concessão de uma tutela jurisdicional mediante técnica específica ou diferenciada em virtude de um quadro processual que demonstra a alta probabilidade de acolhimento da pretensão da parte postulante. De forma mais simples, é um pressuposto fático de uma técnica processual para a obtenção da tutela, configurado quando presentes elementos tipificados pelo legislador como aptos a revelar grande expectativa de vitória. Trata-se de um estado processual em que as afirmações de fato estão devidamente retratadas nos autos (DIDIER JUNIOR; BRAGA; OLIVEIRA, 2018, p. $710)$.

Daí surge a tutela de evidência como técnica processual que apresenta evidências em seu mais elevado grau de clarividência. Uma espécie de direito evidenciado por provas robustas e, se não irretorquível, ao menos dificilmente superáveis. Para esses, a inadequação do procedimento ordinário se revela de pronto para a entrega da prestação jurisdicional, reclamando uma atuação tão pronta quanto evidente o direito da parte. Os ritualismos do procedimento ordinário não se justificam mais frente às novas configurações sociais de conflito da sociedade contemporânea (FUX, 1996, p. 29).

O legislador de 2015, ao editar o atual Código de Processo Civil (Lei no 13.105 de 2015), disciplinou o instituto no Título III (DA TUTELA DA EVIDÊNCIA) do Livro V (DA TUTELA PROVISÓRIA), consubstanciado em um único artigo:

Art. 311. Atutela da evidência será concedida, independentemente da demonstração de perigo de dano ou de risco ao resultado útil do processo, quando: 
I - ficar caracterizado o abuso do direito de defesa ou o manifesto propósito protelatório da parte;

II - as alegações de fato puderem ser comprovadas apenas documentalmente e houver tese firmada em julgamento de casos repetitivos ou em súmula vinculante; III - se tratar de pedido reipersecutório fundado em prova documental adequada do contrato de depósito, caso em que será decretada a ordem de entrega do objeto custodiado, sob cominação de multa;

IV - a petição inicial for instruída com prova documental suficiente dos fatos constitutivos do direito do autor, a que o réu não oponha prova capaz de gerar dúvida razoável.

Parágrafo único - Nas hipóteses dos incisos II e III, o juiz poderá decidir liminarmente (BRASIL, 2015).

No caput do artigo 311, o legislador de 2015 expôs de forma inequívoca que a tutela da evidência prescinde da demonstração de um quadro de periculum in mora. Não exige a comprovação de uma situação de perigo de dano ou de risco à utilidade do próprio processo. A constatação de um cenário de ameaça de prejuízos diante da lerdeza processual, portanto, é perfeitamente dispensável.

$\mathrm{O}$ artigo 311, entretanto, exige para a concessão da tutela da evidência a demonstração nos autos de qualquer uma das hipóteses de evidência do direito tipificadas nos seus quatro incisos.

$\mathrm{Na}$ hipótese do inciso I, é preciso estar demonstrado nos autos um quadro de abuso de direito de defesa ou, alternativamente, a prática de atos procrastinatório pela parte adversa com o intuito de dilatar a tramitação processual e retardar o julgamento da causa, atitudes estas não apenas sancionáveis como atos de litigância de má-fé, mas também enquadráveis como comportamentos típicos de quem reconhece a vitória alheia. E é desta conduta desleal que são extraídos os elementos que resultam na formação de um cenário de evidência do direito da parte postulante.

No inciso II, o legislador de 2015 procurou prestigiar alguns dos precedentes judiciais oriundos do sistema consagrado no artigo 927 do CPC (stare decisis brasiliensis), estipulando que a tutela da evidência deve ser concedida na hipótese de restar comprovadas nos autos as alegações fáticas da parte postulante por meio de documentos e, ainda, o correspondente direito estiver agasalhado em precedente oriundo de súmula vinculante do Supremo Tribunal Federal ou de tese produzida por meio de julgamento de recursos repetitivos ou em incidente de resolução de demandas repetitivas. Lamentavelmente, o legislador foi muito tímido no respectivo dispositivo, deixando de fora outras modalidades de precedentes relacionados nos incisos do artigo 927 do CPC, como aqueles oriundos de acórdãos resultantes do exercício do controle concentrado da constitucionalidade das leis pelo STF e também as teses consagradas no julgamento de incidentes de assunção de competência.

A hipótese do inciso III, por seu turno, é de aplicação restrita às relações fundadas em contrato de depósito. Segundo o tipo legal de quadro de evidência, incumbe ao depositante ou proprietário de um bem custodiado, demonstrar nos autos a existência do respectivo negócio jurídico e a resistência do depositário em entregar o bem, para então ter o seu pedido reipersecutório 
atendido de plano.

O inciso IV do artigo 311 do CPC, por sua vez, traduz a hipótese legal de evidência do direito mais apto a atender situações práticas encontradas nos meios forenses. Caracterizado nos autos um quadro no qual o autor demonstrou o fato constitutivo do seu direito por meio de documentos "suficientes" e o réu, tendo oportunidade para se opor à pretensão do primeiro, foi incapaz de produzir provas aptas a criar na mente do julgador uma "dúvida razoável”, autorizado estará o juiz para conceder a tutela provisória da evidência.

Didier Junior, Braga e Oliveira (2018) afirmam que, com base nas hipóteses de tutela da evidência acima descritas, pode-se falar em duas modalidades de tutela provisória de evidência: a punitiva e a documentada. A punitiva se dá "quando ficar caracterizado o abuso do direito de defesa ou o manifesto propósito protelatório da parte" (DIDIER JUNIOR; BRAGA; OLIVEIRA, 2018, p. 713). E a documentada, "quando há prova documental das alegações de fato da parte, nas hipóteses do art. 311, II a IV, que determinam a probabilidade de acolhimento da pretensão processual" (DIDIER JUNIOR; BRAGA; OLIVEIRA, 2018, p. 713). Completam também que "qualquer espécie de tutela jurisdicional, encarada como resultado prático da decisão pode, em tese, ser beneficiada por essa técnica". Assim, a evidência pode servir às tutelas definitivas ou “provisórias” (DIDIER JUNIOR; BRAGA; OLIVEIRA, 2018, p. 710-711).

A disciplina apresentada no CPC de 2015, portanto, revela que a tutela provisória da evidência constitui um instrumento por meio do qual o juiz, quando demonstrado nos autos um cenário enquadrável em uma das hipóteses legais tipificadas nos incisos do artigo 311 o CPC, deverá deferir um provimento que enseja o adiantamento dos efeitos da tutela final pretendida, de modo a promover a entrega de uma prestação jurisdicional precária diante do quadro de evidência do direito da parte beneficiada, proporcionando uma distribuição mais equânime do ônus do tempo sobre o processo.

Como consequência, a tutela da evidência, a qual se aplicam as regras gerais dos artigos 294 a 299 acerca da tutela provisória, é caracterizada pela provisoriedade, a precariedade (mutabilidade e revogabilidade) e a sumariedade da cognição: "Em todas as hipóteses, a tutela da evidência exige um juízo de probabilidade firme da existência dos fatos alegados pelo autor, da existência do seu direito e da juridicidade e adequação do pedido, cujo acolhimento provisório e antecipado é pleiteado." (GRECO, 2015, p. 204).

Quanto à sua finalidade, afirma Ferreira (2016, p. 25):

Um sistema processual civil que não proporcione à sociedade o reconhecimento e a realização dos direitos, ameaçados ou violados, que têm cada um dos jurisdicionados, não se harmoniza com as garantias constitucionais de um Estado Democrático de Direito. Sendo ineficiente o sistema processual, todo o ordenamento jurídico passa a carecer de real efetividade. [...] O novo Código de Processo Civil tem o potencial de gerar um processo mais célere, mais justo, porque mais rente às necessidades sociais e muito menos complexo. O Novo CPC agora deixa clara a possibilidade de concessão de tutela de urgência e de tutela à evidência. Considerou-se conveniente esclarecer de forma expressa que a resposta 
do Poder Judiciário deve ser rápida não só em situações em que a urgência decorre do risco de eficácia do processo e do eventual perecimento do próprio direito. Também em hipóteses em que as alegações da parte se revelam de juridicidade ostensiva deve a tutela ser antecipadamente (total ou parcialmente) concedida, independentemente de periculum in mora, por não haver razão relevante para a espera, até porque, via de regra, a demora do processo gera agravamento do dano.

A tutela da evidência destarte, se destina a servir como uma ferramenta capaz de melhor distribuir o ônus da passagem do tempo sobre o processo, de modo a beneficiar aquele que pleiteia uma prestação jurisdicional e demonstra nos autos um cenário enquadrável nas hipóteses tipificadas pelo legislador como de grande probabilidade de acolhimento de sua pretensão, e, assim, se apresenta como apto a receber a proteção estatal mediante a efetivação no todo ou em parte dos efeitos da tutela final pretendida.

Luiz Fux (2011, p. 18), por seu turno, comenta que:

A novidade também se operou quanto aos direitos líquidos e certos de uma parte em face da outra. Entendeu a comissão que nessas hipóteses em que uma parte ostenta direito evidente, não se revelaria justo, no ângulo do princípio da isonomia, postergar a satisfação daquele que se apresenta no processo com melhor direito, calcado em prova inequívoca, favorecendo a parte que, ao menos prima facie, não tem razão. A tutela de evidência não é senão a tutela antecipada que dispensa o risco de dano para ser deferida, na medida em que se funda em direito irretorquível da parte que inicia a demanda.

Pode ser observada, assim, a plausibilidade na modificação do sistema referente a tutelas provisórias, tendo como objetivo a necessidade de garantia às partes um processo "célere", uma vez que se trata do cumprimento da Emenda Constitucional no 45 (TUCCI, 1999, p. 236), que acrescenta o inciso LXXVIII ao art. $5^{\circ}$ da Constituição Federal, consagrando o direito fundamental à tutela jurisdicional efetiva, implicando necessariamente no direito à razoável duração do processo: "a todos, no âmbito judicial e administrativo, são assegurados a razoável duração do processo e os meios que garantam a celeridade de sua tramitação". A tutela de evidência tem por finalidade interligar o Processo Civil às garantias fundamentais expressas na Carta Magna, a exemplo das garantias do acesso à justiça, da duração razoável do processo e da efetividade processual, características estas em que se visualizam significativos avanços se comparadas com as do CPC anterior.

Eduardo José da Fonseca Costa (2010, p. 455) entende que, nos casos de tutela de evidência, por exemplo, o juiz defronta-se com uma pretensão de direito material cuja existência é quase certa. Isso é muito comum, por exemplo, nas demandas em que a petição inicial já conta com provas robustas, ou pré-constituídas, dos fatos constitutivos do direito alegado pelo autor.

Relevante também é o pensamento de Guilherme Rizzo Amaral (2015, p. 415-416), 
quando ele explica que a tutela de evidência pode ser definida como a tutela das posições jurídicas prováveis. Isso significa que, por meio de juízo de probabilidade, o juiz determinará, antes da sentença de mérito, quem provavelmente possui razão, e distribuirá o ônus do tempo no processo de tal forma que este (quem provavelmente possui razão) não o carregue. Isso permite que a parte que provavelmente detêm o direito postulado em juízo o usufrua provisoriamente, até que se inverta tal probabilidade - com o desenvolvimento da atividade cognitiva (probatória) - ou se complete a cognição e esteja apto o juiz a prolatar sentença definitiva, substituindo a tutela da evidência concedida anteriormente.

A fim de se iniciar a finalização desta seção e se partir para a de mandado de segurança, é importante que se note a observação de Greco (2015) acerca da tutela de evidência. Ele reforma o fato de a tutela de evidência ser sempre incidente. Pode ser requerida na inicial ou em petição avulsa. Neste último caso, ao réu deverá ser dada oportunidade de respondê-la. Nas hipóteses dos incisos II e III, se a situação fático-jurídica descrita pelo autor estiver documentalmente comprovada, a elevada qualidade do seu direito e a reduzida probabilidade de que o réu possa vir a desmenti-la, ensejam a tutela da evidência por meio de provimento liminar. Nas demais (incisos I e IV), a evidência resulta em grande parte do comportamento do réu ou das provas por ele produzidas e, por isso, o legislador não admite a possibilidade de provimento inaudita altera parte, somente podendo ser concedida depois de decorrido o prazo de resposta do réu (GREGO, 2015, p. 205).

Neste sentido, aliás, dois dispositivos no CPC de 2015. Primeiro, parágrafo único, inciso II, do artigo $9^{\circ}$, ao tratar das restrições de concessão de decisões liminares:

Art. 9ํNão se proferirá decisão contra uma das partes sem que ela seja previamente ouvida.

Parágrafo único. O disposto no caput não se aplica:

I - à tutela provisória de urgência;

II - às hipóteses de tutela da evidência previstas no art. 311, incisos II e III; III - à decisão prevista no art. 701 (BRASIL, 2015).

E, ainda, o parágrafo único do artigo 311, ao repetir a mesma diretriz: Nas hipóteses dos incisos II e III, o juiz poderá decidir liminarmente.

Chama-nos a atenção a possibilidade de a tutela de evidência poder ser concedida em caráter liminar a depender da qualidade do direito.

\section{CONCESSÃO LIMINAR}

O adjetivo "liminar" provém do latim limindris, sendo relativo a soleira, inicial (HOUAISS; VILLAR, 2001, p. 1.759). Corresponde ao qualificativo atribuído à medida ou à decisão concedida 
sob duas condições: a) initio litis, ou seja, logo na abertura ou início da lide processual; e b) inaudita altera parte, isto é, sem antes ouvir a parte adversária. Apesar de ser um adjetivo, a expressão é frequentemente utilizada na doutrina e na jurisprudência como um substantivo, em virtude do costume forense de tratamento.

Liminar, nesse sentido, é um provimento ou uma ordem judicial provisória, concedido logo no início do processo e sem ouvir a parte adversa, cuja efetivação se justifica com base no caráter de perplexidade da lei frente a um fato jurídico com provável veracidade dos fundamentos (fumus boni juris) pelo requerente e da possibilidade de ocorrer dano grave ou irreparável (periculum in mora) em decorrência da demora da decisão judicial. A medida liminar é interina e precária, uma vez que o provimento pode ser modificado ou revogada a qualquer tempo durante o curso do processo, uma vez que o direito sob análise pode ou não ser reconhecido até julgamento de mérito da causa na sentença.

A tutela de evidência por liminar ocorre quando há a possibilidade de sua concessão nos casos das hipóteses de as "alegações de fato puderem ser comprovadas apenas documentalmente e houver tese firmada em julgamento de casos repetitivos ou em súmula vinculante; e a petição inicial for instruída com prova documental suficiente dos fatos constitutivos do direito do autor, a que o réu não oponha prova capaz de gerar dúvida razoável”, incisos II e IV do art. 311 do CPC como visto anteriormente.

Importante ressalvar que merece destaque a "liminar" no CPC de 1939 (Decreto-Lei 1608), especialmente os seguintes dispositivos:

\section{TÍTULO XIII - DAS AÇÕES POSSESSÓRIAS, CAPÍTULO I - DOS INTERDITOS DE MANUTENÇÃO E REINTEGRAÇÃO:}

Art. 371. Si a turbação ou violência datar de menos de ano e dia, o autor poderá requerer mandado de manutenção ou de reintegração initio litis, provando, desde logo:

Art. 373. Concedida, ou não, a manutenção ou reintegração liminar, o autor, nos cinco (5) dias subsequentes, promoverá a citação do réu para contestar dentro de $\operatorname{dez}(10)$ dias [...] (BRASIL, 2015).

Já na "liminar" no CPC de 1973, destacam-se o artigo 928 (medida liminar em ações possessórias) e o artigo 804 (liminar em ação cautelar). A esse respeito, Humberto Theodoro Junior (2009, p. 362-363) esclarece que a inovação mais importante instituída no antigo Código de Processo Civil de 1973 pela Lei no 8.952 de 1994 foi, sem dúvida, a então denominada "antecipação de tutela". Tal técnica de concessão da tutela jurisdicional passou a autorizar ao juiz, em caráter geral, a concessão de medida liminar satisfativa em qualquer ação de conhecimento, desde que preenchidos os requisitos que passaram a ser elencados no texto modificado do artigo 273 do respectivo diploma processual. A propósito, convém ressaltar que, nas principais fontes do direito europeu contemporâneo, o reconhecimento de modificado ou revogado qualquer, além da tutela cautelar destinada a assegurar a efetividade do resultado final do processo principal, deve existir, 
em determinadas circunstâncias, o poder do juiz de antecipar, provisoriamente, a própria solução definitiva esperada no processo principal. São reclamos de justiça que fazem com que a realização do direito não possa, em determinados casos, aguardar a longa e inevitável demora da sentença final.

Com a Lei n 8.952 de 1994, assim, foi introduzida no modelo processual brasileiro a sistematização estrutural da antecipação de tutela em caráter genérico. Noutras palavras, a aplicação, em tese, a qualquer procedimento de cognição, sob a forma de medida liminar deferível sem necessidade de observância do rito das medidas cautelares.

Não se pode deixar de mencionar ainda o artigo 461 e seu $\S 3^{\circ}$, relativo a ações envolvendo prestação de fazer ou não fazer, introduzido no CPC pela mesma Lei:

$\S 3^{\circ}$ Sendo relevante o fundamento da demanda e havendo justificado receio de ineficácia do provimento final, é lícito ao juiz conceder a tutela liminarmente ou mediante justificação prévia, citado o réu. A medida liminar poderá ser revogada ou modificada, a qualquer tempo, em decisão fundamentada (BRASIL, 2015).

Importante se faz também a posição de liminar no CPC de 2015, destacando o artigo $9^{\circ}$ e o artigo 562:

Art. 562. Estando a petição inicial devidamente instruída, o juiz deferirá, sem ouvir o réu, a expedição do mandado liminar de manutenção ou de reintegração, caso contrário, determinará que o autor justifique previamente o alegado, citandose o réu para comparecer à audiência que for designada.

Parágrafo único. Contra as pessoas jurídicas de direito público não será deferida a manutenção ou a reintegração liminar sem prévia audiência dos respectivos representantes judiciais (BRASIL, 2015).

Verifica-se, também, uma estreita relação entre os mecanismos anteriormente citados e o mandado de segurança. Este é um remédio constitucional cabível para:

[...] proteger direito líquido e certo, não amparado por habeas corpus ou habeas data, sempre que, ilegalmente ou com abuso de poder, qualquer pessoa física ou jurídica sofrer violação ou houver justo receio de sofrê-la por parte de autoridade, seja de que categoria for e sejam quais forem as funções que exerça (BRASIL, 2009 , art. $\left.1^{\circ}\right)$.

O mandado de segurança é uma ação sujeita a rito próprio, sendo disciplinado pela Lei ${ }^{\circ}$ 12.016 de 2009, norma esta que sucedeu ao procedimento previsto na Lei $\mathrm{n}^{\circ} .1 .533 / 51$, que vigorou por quase meio século, delineada sua aplicação pelo art. $5^{\circ}$, incisos LXIX e LXX da CR/88.

A partir de então, pode-se questionar um ponto que tem causado dúvida: há possibilidade de tutela de evidência por liminar para suspender a exigibilidade de crédito tributário, uma vez que o art. 151, IV, do Código Tributário Nacional, só aventar a possibilidade de liminar, expressamente, 
em sede de mandado de segurança? A nosso ver, trata-se de um meio bastante pertinente para a suspensão do crédito tributário.

\section{SUSPENSÃO DO CRÉDITO TRIBUTÁRIO}

O crédito tributário nasce a partir do momento em que o contribuinte, ao cometer ou realizar a hipótese de incidência, ou o que a gente denomina de fato gerador, nasce a obrigação tributária. Trata-se de uma relação jurídico-tributária, portanto; uma relação simples de crédito e débito, onde de um lado se tem um credor e, do outro, um devedor. A partir desse momento, o ente público pode exigir o pagamento dessa relação obrigacional, e é através do lançamento que é realizada essa cobrança. O lançamento é, então, a constituição definitiva do crédito tributário. $\mathrm{O}$ contribuinte tem, portanto, dois caminhos a seguir: pagar ou não. Se ele pagar, o crédito tributário é extinto. Em caso negativo, medidas de exigência acabam se tornando realidade frente a esse contribuinte: inclusão em nome de dívida ativa, adoção de medidas jurídicas como a execução fiscal etc. (CARVALHO, 2018, p. 597).

O legislador, todavia, no artigo 141 do CTN, disciplina restrições quanto à forma de afetar o crédito tributário:

Art. 141. O crédito tributário regularmente constituído somente se modifica ou extingue, ou tem sua exigibilidade suspensa ou excluída, nos casos previstos nesta Lei, fora dos quais não podem ser dispensadas, sob pena de responsabilidade funcional na forma da lei, a sua efetivação ou as respectivas garantias (BRASIL, 1966).

Pode, assim, o crédito tributário, ter suspensa a sua exigência. O artigo 151 elenca as formas por meio das quais é possível promover a suspensão da exigibilidade do crédito tributário como sendo as seguintes:

Art. 151. Suspendem a exigibilidade do crédito tributário:

I - moratória;

II - o depósito do seu montante integral;

III - as reclamações e os recursos, nos termos das leis reguladoras do processo tributário administrativo;

IV - a concessão de medida liminar em mandado de segurança.

$\mathrm{V}$ - a concessão de medida liminar ou de tutela antecipada, em outras espécies de ação judicial;

VI - o parcelamento (BRASIL, 1966).

Pretende-se se ater aqui aos incisos IV e V. A suspensão do crédito tributário pode advir de medida com o fito de suspender a exigência do crédito tributário. Então, o contribuinte pode 
requerer a concessão de uma liminar em mandado de segurança ou uma tutela. Para isso, não se deve esquecer a necessidade de se demonstrar o relevante fundamento do pedido e a ineficácia da medida, o fumus boni iuris e o periculum in mora para que o juiz conceda a medida liminar em mandado de segurança, que suspenderá a exigência do crédito. A suspensão, neste sentido, é oriunda de uma decisão judicial que beneficia o contribuinte. Antes de se prosseguir, vale lembrar que a concessão de liminar está prevista no art. $7^{\circ}$ da Lei 12.016, a Lei do Mandado de Segurança (CARVALHO, 2018, p.532).

Situação semelhante se dá com a concessão de tutela provisória, prevista no art. 273 do CPC. Este prevê como verossimilhança da alegação e o fundado receio de dano irreparável: fumus boni iuris e o periculum in mora. Prevendo o juiz esses fundamentos, também será concedida a suspensão da exigibilidade do crédito tributário (CARVALHO, 2018, p. 668).

Em ambos os casos supra, significa dizer que o FISCO está impedido de autuar o contribuindo no tocante à exigibilidade do crédito tributário; também está impedido de inscrever o contribuinte na dívida ativa, de ajuizar a execução fiscal, suspende-se o prazo prescricional e se garante ao contribuinte uma certidão positiva com efeitos de negativa. Todavia, a título de esclarecimento, vale ressaltar que essa suspensão da exigibilidade não impede o lançamento do crédito, não suspende nem interrompe a decadência e não dispensa o cumprimento de obrigações acessórias (CARVALHO, 2018, p. 574).

Considerando o examinado anteriormente, questiona-se: É possível a concessão da tutela de evidência por liminar em mandado de segurança?

Não há dúvida de que, de ordinário, medida liminar em mandado de segurança é provimento que se enquadra no capítulo das cautelares. Isso significa dizer que tende a assegurar um dado direito, e não o satisfazer de forma antecipada.

Paulo César Conrado (2016) explica que, em matéria tributária, acentuaram essa premissa as restrições trazidas pelo artigo $7^{\circ}$, parágrafo $2^{\circ}$, da Lei ${ }^{\circ} 12.016$ de 2009 , preceito que, em sua primeira parte, afirma que "não será concedida medida liminar que tenha por objeto a compensação de créditos tributários, a entrega de mercadorias e bens provenientes do exterior [...]": "essas restrições são facilmente compreendidas se se considerar que, como sublinhado, medida liminar em mandado de segurança é provimento de natureza cautelar, afigurando-se inviável, daí, sua eventual satisfatividade."

Ocorre que, em sua lógica, para concessão da tutela de evidência, dispensa-se a demonstração de perigo de dano ou de risco ao resultado útil do processo (caput do mesmo artigo 311), exigindo-se, em contrapartida a caracterização de uma dentre as quatro hipóteses descritas nos incisos. Dessas hipóteses, uma é de realçada importância para o direito tributário: a inscrita no inciso II, que afirma viável a outorga do provimento se "as alegações de fato puderem ser comprovadas apenas documentalmente e houver tese firmada em julgamento de casos repetitivos ou em súmula vinculante". Como o CPC/2015 não define, materialmente, os efeitos 
extraíveis da tutela de evidência (deixando de apontar, por outros termos, se a providência por ela aparelhada é cautelar ou satisfativa), fica a questão desde logo: o jurisdicionado pode pedir tutela de evidência apenas para um, para outro ou para ambos os fins? Em princípio, poderíamos dizer que, por não restritivo, o novo estatuto caminharia para uma posição mais abrangente, contemplando, via tutela de evidência, tanto as providências cautelares como as satisfativas. Se assim for, partindo-se da premissa (já assentada) de que liminar em mandado de segurança é submodelo de cautelar, o que se poderia concluir é, para além das condições gerais fixadas nos incisos do artigo $7^{\circ}$ da Lei 12.016/2009[2], seria possível a concessão da aludida medida sob o regime do artigo 311 (especificamente em seu inciso II). Ter-se-ia, com isso, uma variante à "clássica" medida liminar em mandado de segurança, que se caracterizaria, inovadoramente, pela irrelevância do periculum in mora (CONRADO, 2016).

Em relação à exigibilidade do crédito tributário, temos a observância que é a partir do lançamento do crédito tributário que a obrigação passa a ser exigível ao sujeito passivo, sendo ele o contribuinte, como elucidado anteriormente. A esse respeito, Paulo de Barros Carvalho (2018, p. 282) leciona que o direito que o credor tem de postular, efetivamente, o objeto da obrigação, e isso tão só ocorre, pois são óbvias, depois de tomadas as providências necessárias à constituição da dívida, com a lavratura do ato de lançamento. No período que antecede tal expediente, ainda não se tem o surgimento da obrigação tributária, inexistindo, consequentemente, crédito tributário, o qual nasce com o ato do lançamento tributário.

Neste entendimento, a suspensão da exigibilidade tem o condão de impossibilitar o FISCO na promoção de atos de cobrança do crédito respectivo da obrigação tributária. Por sua vez, o CTN, em seu art. 151, incisos IV e V, elenca que a concessão de medida liminar em mandado de segurança e a concessão de medida liminar ou de tutela provisória em outras espécies de ação judicial suspendem a exigibilidade do crédito tributário. Filipe Reis Caldas (2016) afirma que:

Apesar do entendimento majoritário, corrente considerável da doutrina e jurisprudência tem se inclinado pela flexibilização das hipóteses de suspensão da exigibilidade do crédito tributário, art. 151, do CTN. Nesse sentido, entende Íris Vânia Santos Rosa[5] afirmando ser possível admitir novas possibilidades, lastreada em princípios constitucionais, podendo ser aplicadas por analogia às existentes. $\mathrm{O}$ próprio STJ admite certa flexibilização das hipóteses de suspensão da exigibilidade, afirmando que o pedido administrativo de compensação de tributo suspende a exigibilidade e impede o ajuizamento da execução fiscal. Nesse sentido:

"EMENTA: AGRAVO REGIMENTAL EM RECURSO ESPECIAL. TRIBUTÁRIO. EMBARGOSÀ EXECUÇÃO FISCAL. PEDIDO DE COMPENSAÇÃO. CAUSA DE SUSPENSÃO DA EXIGIBILIDADE DO CRÉDITO TRIBUTÁRIO. EXECUÇÃO FISCAL. CITAÇÃO DO EXECUTADO E CONTRATAÇÃO DE ADVOGADO PARA OPOSIÇÃO DE EXCEÇÃO DE PRÉ-EXECUTIVIDADE. VERBA HONORÁRIA A SER SUPORTADA PELA FAZENDA. CABIMENTO. AGRAVO REGIMENTAL 
IMPROVIDO. 1. É firme o entendimento do Superior Tribunal de Justiça em que o pedido administrativo de compensação de tributos possui o condão de suspender a exigibilidade do crédito tributário, nos termos do art. 151, inciso III, do Código Tributário Nacional. Precedentes. 2. São devidos honorários advocatícios contra Fazenda Pública se a execução fiscal foi extinta após a citação do devedor e, em especial, se houve a contratação do advogado para que fosse apresentada exceção de pré-executividade. Precedentes. 3. Agravo regimental improvido." (AgRg no REsp 1192182/PR, Rel. min. HAMILTON CARVALHIDO, primeira turma, julgado em 24/08/2010, DJe 04/10/2010)

$\mathrm{O}$ pedido de compensação não se trata de impugnação nem de recurso administrativo, sendo uma nova hipótese não elencada no art. 151 do CTN e amplamente aceita pela doutrina e jurisprudência do STJ como causa de suspensão da exigibilidade do crédito tributário, ressaltando assim a posição adotada mesmo que discretamente pela flexibilização das hipóteses de suspensão. O próprio artigo 151 do CTN possui dois incisos afirmando ser possível a concessão de liminares como hipóteses de suspensão da exigibilidade, inciso IV e V. Como o Direito Tributário não possui um código de processo tributário específico, muitas de suas disposições processuais se amparam na utilização do Código de Processo Civil naquilo que não lhe seja contrário, sendo lá estipulado a definição, conteúdo e alcance das liminares.

Importante destacar que no Fórum Permanente de Processualistas, realizado nos dias 18, 19 e 20 de março de 2016 na cidade de São Paulo, foi aprovado o Enunciado n ${ }^{\circ} 422$ do respectivo fórum, dispondo, que "A tutela de evidência por sua vez é compatível com os procedimentos especiais". Tal entendimento se direciona para a compatibilidade entre tutela de evidência, e o seu cabimento em sede de liminar no mandado de segurança.

Didier Junior, Braga e Oliveira (2018, p. 738) citam Eduardo Talamini para observarem que, independentemente de toda essa discussão doutrinária e das mudanças legislativas, devese frisar que não é possível conceder provisoriamente providência que compensa ou extingue o débito, pelo simples fato de que não se antecipa (des) constituição de situação jurídica - o que já seria a tutela definitiva. Mas nada impede que se adiantem os seus efeitos práticos e sociais, isto é, a suspensão de exigibilidade do crédito.

\section{CONCLUSÃO}

A tutela provisória da evidência, disciplinado no artigo 311 CPC de 2015, corresponde a uma tutela jurisdicional antecipatória concedida diante da demonstração dos autos de um quadro de "evidência do direito", no qual é reconhecida a alta probabilidade de acolhimento da pretensão da parte postulante. Tal espécie do gênero tutela provisória se diferencia da outra espécie, a tutela de urgência, pois esta exige como principal fundamento de concessão a demonstração da existência de um quadro de periculum in mora, caracterizado pelo risco de dano ou ameaça à utilidade do processo. Traços distintivos é a possibilidade de a tutela de urgência ser de natureza cautelar ou de índole antecipatória e poder ser concedida de modo incidental ou de forma antecedente 
à formulação do pedido de tutela final, enquanto a tutela da evidência é sempre materializada por meio de uma medida de caráter antecipatória, implicando no adiamento dos efeitos da tutela final pretendida, e ser sempre concedido incidentalmente, no curso do processo, e não de forma antecedente.

Outra diferença é que, à luz do artigo $9^{\circ}$, parágrafo único, inciso I, do CPC, a tutela de urgência em tese poderá sempre concedida de forma liminar, ou seja, de forma geral a medida pode ser ordenada pelo juiz initio litis e inaudita altera parte, condicionado apenas à satisfação dos requisitos gerais de probabilidade do direito e de demonstração da existência do periculum in mora. A tutela da evidência, por outro lado, somente em determinados casos pode ser concedida liminarmente, conforme delineado pelo inciso II do mesmo parágrafo único do artigo $9^{\circ}$, e, ainda, o parágrafo único do artigo 311 do CPC.

Nesse sentido, os mencionados dispositivos legais autorizam a concessão de medida liminar em sede de tutela da evidência em duas hipóteses. Primeiro, pode ocorrer a concessão initio litis e inaudita altera parte nos casos da hipótese do inciso II do artigo 311, quando as alegações de fato puderem ser comprovadas apenas documentalmente e houver tese firmada em julgamento de casos repetitivos ou em súmula vinculante. E, segundo, pode também ocorrer a concessão liminar nos casos da hipótese do inciso III do mesmo artigo 311. Quando a petição inicial for instruída com prova documental suficiente dos fatos constitutivos do direito do autor, a que o réu não oponha prova capaz de gerar dúvida razoável.

Essas duas hipóteses relacionadas nos incisos II e III do artigo 311 do código de ritos de 2015, entretanto, não correspondem às únicas formas de se conseguir liminarmente a tutela da evidência, mesmo diante da aparência de uma relação taxativa e exauriente repetida em dois dispositivos distintos (os já mencionados parágrafos únicos dos artigos $9^{\circ}$ e 311 do CPC). A medida liminar concedida em sede de mandado de segurança pode igualmente corresponder a uma tutela de evidência concretizada mediante uma concessão liminar do respectivo magistrado.

O mandado de segurança é um remédio constitucional cabível para proteger direito líquido e certo, não amparado por habeas corpus ou habeas data, sempre que, ilegalmente ou com abuso de poder, qualquer pessoa física ou jurídica sofrer violação ou houver justo receio de sofrêla por parte de autoridade, seja de que categoria for e sejam quais forem as funções que exerça, conforme a Lei 12.016.

Nos termos do inciso IV, do artigo 151, do Código Tributário Nacional, a medida liminar em mandado de segurança é causa de suspensão de exigibilidade do crédito tributário. E tal provimento assume a forma de uma tutela de evidência. Isso significa dizer que a concessão liminar da tutela da evidência em mandado de segurança é extremamente pertinente em matéria tributária. Um remédio constitucional que abre espaço para a tutela provisória, mesmo diante da postura restritiva do legislador de 2015 nos textos normativos dos parágrafos únicos dos artigos $9^{\circ}$ e 311 do CPC.

No Fórum Permanente de Processualistas de 2016, foi aprovado o Enunciado $n^{\circ} 422$ 
do respectivo fórum, dispondo, que a tutela de evidência por sua vez é compatível com os procedimentos especiais. Tal entendimento se direciona para a compatibilidade entre tutela de evidência, e o seu cabimento em sede de liminar no mandado de segurança.

Doutrinadores renomados explicam que, independentemente de toda essa discussão doutrinária e das mudanças legislativas, deve-se frisar que não é possível conceder provisoriamente providência que compensa ou extingue o débito, pelo simples fato de que não se antecipa (des) constituição de situação jurídica - o que já seria a tutela definitiva. Mas nada impede que se adiantem os seus efeitos práticos e sociais, isto é, a suspensão de exigibilidade do crédito.

\section{REFERÊNCIAS}

AMARAL, Guilherme Rizzo. Comentários às alterações do novo código de processo civil. São Paulo: Revista dos Tribunais, 2015. BRASIL. Planalto. Lei n. 5.172, de 25 de outubro de 1966. Dispõe sobre o Sistema Tributário Nacional e institui normas gerais de direito tributário aplicáveis à União, Estados e Municípios. Brasília, DF: Presidência da República, 1966. Disponível em: www.planalto.gov.br. Acesso em: 10 fev. 2019.

BRASIL. Lei $\mathbf{n}^{\mathbf{0}}$ 12.016, de 7 de agosto de 2009. Disciplina o mandado de segurança individual e coletivo e dá outras providências. Brasília, DF: Presidência da República, 2009. Disponível em: http://www.planalto.gov.br/ccivil_03/_ato2007-2010/2009/lei/112016.htm. Acesso em: 10 fev. 2019.

BRASIL. [Constituição (1988)]. Constituição da República Federativa do Brasil de 1988. Brasília, DF: Presidência da República, 1988. Disponível em: http://www.planalto.gov.br/ ccivil_03/constituicao/constituicao.htm. Acesso em: 10 fev. 2019.

BRASIL. Lei n. 13.105, de 16 de março de 2015. Código de Processo Civil. Brasília, DF: Presidência da República, 2015. Disponível em: http://www.planalto.gov.br/ccivil_03/_Ato20152018/2015/Lei/L13105.htm. Acesso em: 10 fev. 2019.

CALDAS, Filipe Reis. A tutela de evidência e seus reflexos no âmbito do direito tributário. Conteúdo Jurídico, Brasília, DF, 15 set. 2016. Disponível em: https://www.conteudojuridico. com.br/consulta/Artigos/47512/a-tutela-de-evidencia-e-seus-reflexos-no-ambito-do-direitotributario. Acesso em: 10 fev. 2019

CARVALHO, Paulo de Barros. Curso de direito tributário. 29. ed. São Paulo: Saraiva, 2018.

COSTA, Eduardo José da Fonseca. Tutelas de urgência e cautelares. 25. ed. São Paulo: Saraiva, 2010.

CONRADO, Paulo César. Tutela de evidência em mandado de Segurança afeta Direito Tributário. Consultor Jurídico, Brasília, DF, 25 maio 2016. Disponível em: htTps://www. CONJUR.COM.BR/2016-MAI-25/PAULO-CONRADO-TUTELA-EVIDENCIA-MS-AFETA-DIREITO-TRIBUTARIO. ACESSO EM: 15 MAR. 2019. 
DIDIER JÚNIOR, Fredie; BRAGA, Paula Sarno; OLIVEIRA, Rafael. Curso de direito processual civil: teoria da prova, direito probatório, ações probatórias, decisão, precedente, coisa julgada e antecipação dos efeitos da tutela. 13. ed. Salvador: Jus Podivm, 2018. v. 2.

Ferreira, lara lorena. O novo CPC e a velha Fazenda Pública. São Paulo: IBDP, 2016. DiSPONÍVEL EM: WWW.DIREITOPROCESSUAL.ORG.BR. ACESSO EM: 15 MAR. 2019.

FUX, Luiz. O novo processo civil brasileiro: direito em expectativa. Rio de Janeiro: Forense, 2011.

FUX, Luiz. Tutela de segurança e tutela de evidência. São Paulo: Saraiva, 1996.

GRECO, Leonardo. A tutela da urgência e a tutela da evidência no código de processo civil de 2014/2015. Revista Eletrônica de Direito Processual - REDP, Rio de Janeiro, v. XIV, p. 296$330,2015$.

HOUAISS, Antônio; VILLAR, Mauro de Salles. Dicionário Houaiss de Língua Portuguesa. Rio de Janeiro: Objetiva, 2001.

THEODORO JUNIOR, Humberto. Curso de direito processual civil. Rio de Janeiro: Forense, 2009.

TUCCI, Rogério Cruz e. Garantias constitucionais do processo. São Paulo: Editora RT, 1999.

Como citar: TEIXEIRA, Sérgio Torres; ALVES, Enéas César Douetts. Concessão liminar da tutela da evidência em mandado de segurança em matéria tributária. Revista do Direito Público, Londrina, v. 15, n. 2, p. 177-194, ago. 2020. DOI: 10.5433/24157-108104-1.2020v15n2p. 177. ISSN: $1980-511 \mathrm{X}$

Recebido em: 27/06/2019

Aprovado em: 02/07/2020 